Artigo Original

Original Article

Esther Simonato ${ }^{1}$ (B)

Anne Taffin d'Heursel Baldisseri'

Clara Regina Brandão de Avila ${ }^{1}$ (D)

Descritores

Bilinguismo

Multilinguismo

Processos Mentais

Cognição

Leitura

Keywords

Bilingualism

Multilingualism

Mental Processes

Cognition

Reading

Endereço para correspondência:

Esther Simonato

Departamento de Fonoaudiologia,

Universidade Federal de São Paulo -

UNIFESP

Rua Botucatu, 802, Vila Clementino, São Paulo (SP), Brasil, CEP: 04023-

062.

E-mail: esthersimonato@hotmail.com

Recebido em: Julho 22, 2019

Aceito em: Setembro 14, 2020

\section{Bilinguismo e Nomeação Automática Rápida: efeitos da alternância de línguas sobre o acesso lexical e a velocidade de leitura}

\author{
Bilingualism and Rapid Automatized Naming: \\ effects of language switching on lexical access \\ and reading speed
}

\section{RESUMO}

Objetivo: Verificar se o bilinguismo, na condição de alternância de línguas, associa-se à maior ou menor velocidade e precisão na nomeação rápida de objetos e se essa condição se relaciona com a velocidade de leitura de texto. Método: Analisou-se o desempenho de 50 crianças bilíngues sequenciais brasileiras, cuja língua materna era o Português Brasileiro, expostas ao Inglês diariamente no ambiente escolar. O grupo monolíngue, composto por 47 crianças, foi agrupado de acordo com a faixa etária. Foram analisados desempenhos em tarefa de Nomeação Automática Rápida (RAN) e velocidade (palavras lidas por minuto) em prova de leitura oral de texto. Resultados: Os resultados revelaram que a alternância de línguas se associou ao desempenho dos escolares bilíngues na prova de Nomeação Rápida no que diz respeito à velocidade e à precisão. Em condição de alternância de línguas, os escolares bilíngues despenderam mais tempo para nomear e cometeram mais erros. Somente se observou correlação entre o desempenho dos escolares bilíngues na prova de nomeação rápida em L2 e a taxa de leitura em L1. Conclusão: Escolares brasileiros bilíngues apresentaram pior desempenho em tarefa de nomeação rápida na situação de alternância de línguas quando comparados a escolares monolíngues, com maior número de erros, especialmente hesitações.

\begin{abstract}
Purpose: To assess whether bilingualism, on a language switching experiment, is associated with higher or lower accuracy and speed of the rapid automatized naming of objects and investigate the influence of language switching on reading speed. Methods: The performance of 50 Brazilian bilingual children in the Rapid Automatized Naming Task, whose L1 was Brazilian Portuguese and who were exposed to English daily at school, was assessed. Forty-seven monolingual (Brazilian Portuguese) children were grouped according to age. Results: Language switching interfered with the performance of the bilingual children in the Rapid Automatized Naming Task in terms of speed and accuracy. No correlations were found between the performance in the RAN task and Reading Speed. Conclusion: Brazilian bilingual students showed poor performance in the rapid naming task on the switch trial when compared to monolingual students, showing higher rates of mistakes, especially hesitations. Only the performance of bilingual students in the rapid naming task in L2 correlated with L1 reading speed.
\end{abstract}

Trabalho realizado no Departamento de Fonoaudiologia, Escola Paulista de Medicina, Universidade Federal de São Paulo - UNIFESP - São Paulo (SP), Brasil.

${ }^{1}$ Escola Paulista de Medicina, Universidade Federal de São Paulo - UNIFESP - São Paulo (SP), Brasil.

Fonte de financiamento: Bolsa de Iniciação Científica da Fundação de Amparo à Pesquisa do Estado de São Paulo - FAPESP - processo no 2017/20005-8.

Conflito de interesses: nada a declarar. 


\section{INTRODUÇÃO}

O bilinguismo é uma importante ferramenta de comunicação e, com o advento da Globalização, a capacidade de comunicar-se em mais de uma língua tem se tornado habilidade necessária. Por se tratar de um fenômeno complexo e influenciado por diversos fatores ${ }^{(1)}$, a definição de bilinguismo na literatura é variada. No entanto, para os propósitos deste estudo, seguiremos a definição proposta por Grosjean, que descreve o bilinguismo como o "uso regular de duas línguas"(1).

A ciência busca compreender os efeitos do bilinguismo sobre a cognição há anos. Evidencias iniciais, apresentadas a partir da década de 60 , constatavam que crianças bilíngues se sobressaiam em diversas tarefas cognitivas, quando comparadas às monolíngues ${ }^{(2)}$. Em pesquisa recente, concluiu-se que o bilinguismo tem grande impacto sobre as funções cognitivas e que indivíduos bilíngues desenvolvem melhores funções executivas e habilidades metalinguísticas ${ }^{(3)}$. Em contrapartida, outros estudos, que também estudaram os efeitos do bilinguismo sobre a cognição, apontaram que crianças fluentemente bilíngues podem apresentar restrições de vocabulário ${ }^{(4)}$, escores reduzidos em testes de fluência verbal por pista semântica e por pista fonológica $^{(5)}$, além de maior número de erros em tarefas de nomeação de figuras ${ }^{(6)}$, o que pode indicar dificuldades de acesso lexical ${ }^{(3)}$, importante habilidade, também, para o reconhecimento automático de palavras durante a leitura ${ }^{(7)}$. Estudos também apontam que bilíngues apresentam desvantagem em provas de nomeação mesmo quando estas são realizadas em sua língua dominante $^{(8)}$

De acordo com a literatura, ambas as línguas são ativadas no cérebro de indivíduos bilíngues quando se produz uma palavra ou enunciado em qualquer de seus idiomas, como por exemplo durante a fala e a leitura ${ }^{(8,9)}$. As representações semânticas das palavras são compartilhadas entre as línguas e estão conectadas a representações lexicais para cada idioma, separadamente $^{(10)}$. Em razão disso, indivíduos bilíngues se diferenciam dos monolíngues, uma vez que processam o dobro de informações lexicais, durante qualquer atividade linguística ${ }^{(10)}$. Consequentemente, em tarefas que enfatizem o nível lexical, assim como a prova de Nomeação Automática Rápida $^{(11)}$, podemos esperar desempenhos diferentes para indivíduos bilíngues e monolíngues, uma vez que a ativação paralela das representações lexicais em bilíngues pode resultar no fenômeno de competição entre as línguas ${ }^{(12)}$, com possível prejuízo do desempenho desses indivíduos no que se refere à velocidade e acurácia com provável aparecimento de hesitações no acesso lexical ${ }^{(13)}$.

Outro fator importante a ser considerado no estudo do bilinguismo é o fenômeno de alternância do código linguístico. Em situações de comunicação natural, indivíduos bilíngues proficientes são capazes de alternar entre suas línguas de forma flexível ${ }^{(14)}$. A alternância de línguas é um processo dependente da capacidade eficiente do indivíduo de selecionar a língua alvo utilizada durante o momento de comunicação, e inibir a língua não-alvo, mantendo a separação entre seus idiomas ${ }^{(14)}$. No entanto, a alternância de línguas pode resultar em efeitos negativos sobre o desempenho de indivíduos bilíngues, nomeadamente o aumento do tempo de resposta e número de erros em tarefas linguísticas ${ }^{(14)}$. Hipotetiza-se que, durante o processo de alternância de línguas, a seleção da língua previamente inibida requer um período de tempo extra para sua reativação, resultando em custos negativos sobre o desempenho do indivíduo bilíngue ${ }^{(14)}$.

A mensuração da velocidade de acesso lexical pode ser realizada a partir da aplicação da prova de Nomeação Automática Rápida (Rapid Automatized Naming - RAN) ${ }^{(11)}$. Nessa prova, os participantes devem nomear rápida e corretamente estímulos familiares, dispostos de forma sequenciada ${ }^{(11,15)}$. A literatura pertinente refere que a capacidade de nomeação automática rápida está relacionada ao desempenho de leitura ${ }^{(7,11)}$. Portanto, o desempenho na prova de Nomeação Automática Rápida (RAN), avaliado pelos parâmetros de velocidade e precisão de acesso ao léxico, é considerado um dos melhores preditores de fluência leitora para todas as ortografias conhecidas ${ }^{(16)} \mathrm{e}$, muitos dos processos necessários para sua realização, também são necessários para a leitura (como o movimento sacádico dos olhos e conexão de representações, no caso da leitura, ortográficas e fonológicas $\left.{ }^{(15)}\right)$. A automaticidade em cada processo perceptivo e linguístico e a conexão entre eles em tarefas seriadas apresentadas visualmente é a maior razão pela qual a RAN é capaz de prever as habilidades de leitura ${ }^{(15)}$.

Apesar de estudos apontarem que o bilinguismo pode exercer influência sobre a habilidade de acesso ao léxico mental ${ }^{(3,6)}$, a literatura ainda mostra lacunas quando quer esclarecer como os mecanismos subjacentes a esse processo são afetados pela capacidade de comunicar-se em mais de uma língua. Sabemos que a prova de nomeação rápida é capaz de aferir dois aspectos importantes do acesso lexical: a precisão, ou acurácia, e a velocidade. No entanto, não compreendemos se o bilinguismo, em demanda de alternância das línguas, é capaz de agir, diferentemente, sobre esses dois parâmetros, e como isso acontece em comparação com os monolíngues. No presente estudo, investigamos o desempenho de indivíduos bilíngues em tarefa de nomeação automática rápida considerando dois fatores agravantes: a competição ${ }^{(12)}$ entre as línguas e o fenômeno de alternância do código linguístico ${ }^{(14)}$.

Dessa forma, o alvo deste estudo foi averiguar o desempenho de crianças bilíngues e monolíngues em velocidade de acesso lexical, em precisão de nomeação, segundo o tipo de erro ocorrido, e em velocidade da leitura. A hipótese é a de que os bilíngues despenderão mais tempo e errarão mais, uma vez que recebem interferência da segunda língua aprendida na execução das tarefas, e que a alternância de línguas poderá interferir no desempenho dos escolares. Além disso, a hesitação deve ser o tipo de erro mais frequente observado na nomeação rápida nas crianças bilíngues.

Assim, esta pesquisa teve por objetivo investigar se o bilinguismo, na demanda de alternância das línguas, interfere na velocidade ou precisão de nomeação rápida de objetos, considerando o tipo de erro apresentado na nomeação, e verificar se a velocidade de acesso ao léxico mental relaciona-se à velocidade de leitura de texto.

\section{MÉTODOS}

Estudo retrospectivo, de corte transversal e análise quantitativa. Recebeu aprovação do Comitê de Ética em Pesquisa da Universidade 
Federal de São Paulo (nº 1193/2017). Os participantes e seus responsáveis, assinaram os Termos de Consentimento Livre e Esclarecido e todos foram anonimizados.

\section{Seleção da amostra}

Estudaram-se protocolos de avaliação do banco de dados do Núcleo de Ensino, Assistência e Pesquisa em Escrita e Leitura (NEAPEL) da Universidade Federal de São Paulo. Foram selecionados protocolos de avaliação de crianças escolares com idades entre 07 e 09 anos $(n=97, \bar{X}=8,0$, S.D. $=0,5)$, regularmente matriculadas em diferentes escolas da rede particular de ensino do município de São Paulo (SP). Todos os participantes eram brasileiros e tinham o Português Brasileiro como língua materna (L1).

As crianças bilíngues também eram brasileiras, com exposição inicial à Língua Inglesa (L2) a partir dos três anos de idade e não tinham familiaridade com quaisquer outros idiomas que não fossem Português e Inglês. Os escolares eram expostos à segunda língua por ao menos 30 horas semanais, há pelo menos três anos, e estavam alfabetizados nas duas línguas.

Foram excluídos protocolos de crianças que apresentaram queixas, indícios ou diagnóstico relacionados a alterações: sensoriais, auditivas ou visuais (não corrigidas), cognitivas, neurológicas, psiquiátricas, de aprendizagem ou comunicação.

Foram coletados dos protocolos de avaliação, informações sobre sexo e idade dos escolares. No entanto, não foram coletadas informações referentes ao nível socioeconômico e escolaridade dos pais.

As crianças bilíngues foram agrupadas segundo a ordem de aplicação da prova, da seguinte forma: GBP: 23 crianças realizaram a prova em Português (primeiro teste) e, em seguida, em Inglês; GBI: 27 crianças realizaram a prova em Inglês (primeiro teste) e, em seguida, em Português. Quando analisados em conjunto, o grupo de escolares bilíngues foi denominado apenas GB. Os monolíngues foram agrupados de acordo com a idade. A distribuição da amostra total, segundo grupo, idade e sexo está apresentada no Quadro 1.

\section{Instrumento}

Para a avaliação dos escolares, foi utilizada a prova de Nomeação Automática Rápida proposta por Lúcio et al. ${ }^{(11)}$, constituída por duas pranchas, denominadas Parte A e Parte $\mathrm{B}$, nas quais seis figuras coloridas (chave, ovo, bola, garfo, sol e pão) foram distribuídas linearmente, seis vezes em cada prancha, somando 36 aparições por prancha e seguindo ordem

Quadro 1. Distribuição da amostra segundo grupo, idade, sexo e nível escolar

\begin{tabular}{|c|c|c|c|c|}
\hline \multicolumn{2}{|c|}{ Amostra } & Bilíngue & Monolíngue & Total \\
\hline \multirow{4}{*}{ Idade } & 7 & 06 & 12 & 18 \\
\cline { 2 - 5 } & 8 & 32 & 14 & 46 \\
\cline { 2 - 5 } & 9 & 12 & 21 & 33 \\
\cline { 2 - 5 } & Total & 50 & 47 & 97 \\
\hline \multirow{4}{*}{ Sexo } & Feminino & 32 & 24 & 56 \\
\cline { 2 - 5 } & Masculino & 18 & 23 & 41 \\
\cline { 2 - 5 } & Total & 50 & 47 & 97 \\
\hline
\end{tabular}

de apresentação diferente para cada uma das pranchas ${ }^{(14)}$. Os vocábulos selecionados para a construção do instrumento foram determinados a partir de um estudo-piloto, no qual as seis imagens escolhidas foram reconhecidas em $100 \%$ de 15 crianças pré-escolares brasileiras monolíngues. Para a avaliação na segunda língua, foi utilizado o mesmo instrumento, a fim de aproximar a extensão dos vocábulos entre ambas as línguas, já que os vocábulos em Inglês são monossilábicos (key, egg, ball, fork, sun, bread) e em Português são dissilábicos (chave, ovo, bola, garfo), com exceção a dois itens do teste, os quais, assim como em Inglês, são monossilábicos (sol, pão).

\section{Procedimentos de aplicação}

Para a avaliação dos escolares monolíngues, foi apresentada uma prancha treino, contendo as seis figuras coloridas, dispostas sequencialmente em uma folha $\mathrm{A} 4$, no sentido paisagem. Foi solicitado que os estudantes nomeassem as figuras o mais rápido que conseguissem. Ao se familiarizarem com os estímulos, foram apresentadas as pranchas de teste e os escolares foram instruídos a nomear as figuras o mais correto e rapidamente que conseguissem, sem cometer erros, seguindo a ordem de nomeação da esquerda para a direita, do topo ao final da folha. As pranchas foram aplicadas em sequência, isto é, inicialmente foi aplicada a Parte A e, em seguida, foi aplicada a Parte B.

Para a avaliação dos escolares bilíngues, foi utilizada a mesma versão do instrumento aplicado nos escolares monolíngues e o procedimento de avaliação foi idêntico, com exceção da língua utilizada durante o teste. Os escolares bilíngues realizaram a prova em ambas as línguas (Português e Inglês) e a ordem de aplicação do instrumento de foi sorteada aleatoriamente entre os participantes, constituindo dois grupos distintos: GBP (Grupo bilíngue que realizou a prova primeiramente em Português e, posteriormente, em Inglês) e GBI (Grupo bilíngue que realizou a prova primeiramente em Inglês e, posteriormente em Português). Os instrumentos foram aplicados consecutivamente, ou seja, imediatamente após a aplicação das pranchas A e B na língua inicial (GBP: Português; GBI: Inglês), aplicaram-se os mesmos instrumentos (pranchas A e B) na língua final (GBP: Inglês; GBI: Português). Os participantes receberam as instruções no idioma em que seriam testados.

Também foram coletadas informações sobre os valores de taxa na leitura oral de texto realizada pelos escolares. Para a avaliação dos escolares monolíngues, foram retirados textos de livros didáticos (em Português Brasileiro), adequados à série escolar. Para a avaliação dos escolares bilíngues, também foram selecionados textos adequados para cada série escolar (em Inglês) e o procedimento de avaliação foi o mesmo para ambos os grupos. Os textos foram apresentados em folha A4 no modo retrato e os escolares foram instruídas a ler o texto em voz alta. $\mathrm{O}$ avaliador acionou o cronômetro ao início da leitura do segundo parágrafo e interrompeu a leitura do escolar ao atingir a marca de um minuto, registrando graficamente no protocolo a última palavra lida pela criança.

Todas as avaliações foram gravadas digitalmente e os arquivos foram armazenados para análise posterior. 


\section{Análise de dados}

Inicialmente, todas as gravações foram ouvidas e os erros assinalados. Em uma segunda etapa, os erros foram agrupados e classificados segundo a seguinte proposta baseada e adaptada de Kohn e Goodglass ${ }^{(17)}$ : Hesitações: Latência de resposta maior do que dois segundos; Repetições: Duplicação do item imediatamente anterior ao item alvo; Substituição: Troca do item alvo por outro vocábulo, presente ou não na lista de nomeação; Omissão: Omissão/ exclusão completa do item alvo; Intrusão: Intrusão da outra língua durante a prova de nomeação; Autocorreção: Correção imediata realizada pelo escolar quando ocorre erro na emissão do item alvo.

O valor total e os tipos de erros, bem como o tempo total despendido (em segundos) na nomeação das duas pranchas foram registrados em planilha Excel.

As provas de leitura também foram analisadas e o número de palavras lidas foi computado em planilha de excel.

Para a análise descritiva calcularam-se as médias e desviospadrão dos valores das respostas dos escolares, por ano e por grupo.

A análise inferencial foi obtida por meio do teste $t$ de Student para a comparação de dois grupos, e da Análise de Variância (ANOVA), indicado para comparar três ou mais grupos de informações, para identificar possíveis diferenças entre os desempenhos dos grupos. Em casos de não-normalidade, foi utilizado o teste U de Mann-Whitney. O coeficiente de correlação de Spearman também foi calculado para investigar possíveis associações entre as variáveis estudadas. O nível de significância adotado para os testes foi de $5 \%$

\section{RESULTADOS}

A comparação do desempenho dos grupos GBP e GBI quanto ao tempo total despendido na nomeação rápida em L2 mostrou que o GBP foi mais lento ao nomear ambas as pranchas, quando comparado ao GBI. Por outro lado, na nomeação em Português o GBI apresentou médias mais altas para a nomeação apenas da prancha A, apresentando semelhança de desempenho na nomeação da prancha B (Tabela 1).

Quanto à comparação entre GBP e GBI para cada tipo de erro na nomeação rápida (Tabela 2), observou-se que o GBP apresentou mais hesitações do que o GBI na prancha A. No entanto, o desempenho dos grupos foi semelhante para a mesma variável na prancha B. Quanto ao erro de repetição, observaram-se médias mais elevadas para o GBP na prancha A, porém desempenho semelhante na prancha B. Não houve diferença de desempenho entre os grupos para as demais variáveis.

Em relação à comparação entre GB e GM para cada tipo de erro na nomeação rápida (Tabela 3), observou-se que GB apresentou mais hesitações do que GM na nomeação da prancha A, porém mostrou desempenho semelhante ao monolíngue, na prancha $\mathrm{B}$, para a mesma variável. Não foram observadas

Tabela 1. Comparação dos tempos totais despendidos na Nomeação Rápida em Inglês e Português entre GBP $(n=23)$ e GBI $(n=27)$

\begin{tabular}{|c|c|c|c|c|c|c|c|c|c|}
\hline & & \multicolumn{4}{|c|}{ Inglês } & \multicolumn{4}{|c|}{ Português } \\
\hline & & \multicolumn{2}{|c|}{ Prancha A } & \multicolumn{2}{|c|}{ Prancha B } & \multicolumn{2}{|c|}{ Prancha A } & \multicolumn{2}{|c|}{ Prancha B } \\
\hline & & Média & DP & Média & $\mathrm{DP}$ & Média & DP & Média & $\mathrm{DP}$ \\
\hline \multirow[t]{3}{*}{ GB } & GBP & 44,83 & 9,47 & 41,17 & 10,88 & 31,69 & 6,37 & 38,91 & 7,18 \\
\hline & GBI & 31,96 & 4,31 & 35,00 & 6,63 & 43,81 & 8,28 & 41,63 & 8,2 \\
\hline & p-valor & \multicolumn{2}{|c|}{$0,00^{*}$} & \multicolumn{2}{|c|}{$0,018^{*}$} & \multicolumn{2}{|c|}{$0,00^{*}$} & \multicolumn{2}{|c|}{0,22} \\
\hline
\end{tabular}

*Nível de significância: $p=0,05$ - Teste ANOVA

Legenda: GB = Grupo Bilíngue; GBP = Grupo Bilíngue Português; GBI = Grupo Bilíngue Inglês; DP = Desvio-padrão

Tabela 2. Análise das médias e desvios-padrão para cada tipo de erro na Nomeação Rápida, em Inglês, para GBP e GBI

\begin{tabular}{|c|c|c|c|c|c|}
\hline & & & & & p-valor \\
\hline \multirow[t]{8}{*}{ HESITAÇÃO } & Prancha A & GBP & Média & 0,78 & $0,006^{*}$ \\
\hline & & & DP & 1,166 & \\
\hline & & GBI & Média & 0,04 & \\
\hline & & & DP & 0,192 & \\
\hline & Prancha B & GBP & Média & 0,39 & 0,094 \\
\hline & & & DP & 0,839 & \\
\hline & & GBI & Média & 0,07 & \\
\hline & & & DP & 0,267 & \\
\hline \multirow[t]{8}{*}{ REPETIÇÃO } & Prancha A & GBP & Média & 0,74 & $0,008^{*}$ \\
\hline & & & DP & 1,137 & \\
\hline & & GBI & Média & 0,04 & \\
\hline & & & DP & 0,192 & \\
\hline & Prancha B & GBP & Média & 0,61 & 0,059 \\
\hline & & & DP & 1,27 & \\
\hline & & GBI & Média & 0,07 & \\
\hline & & & DP & 0,267 & \\
\hline
\end{tabular}

*Nível de significância: $p=0,05$ - Teste ANOVA

Legenda: GBP = Grupo Bilíngue Português; GBI = Grupo Bilíngue Inglês; DP = Desvio-padrão 
Tabela 2. Continuação...

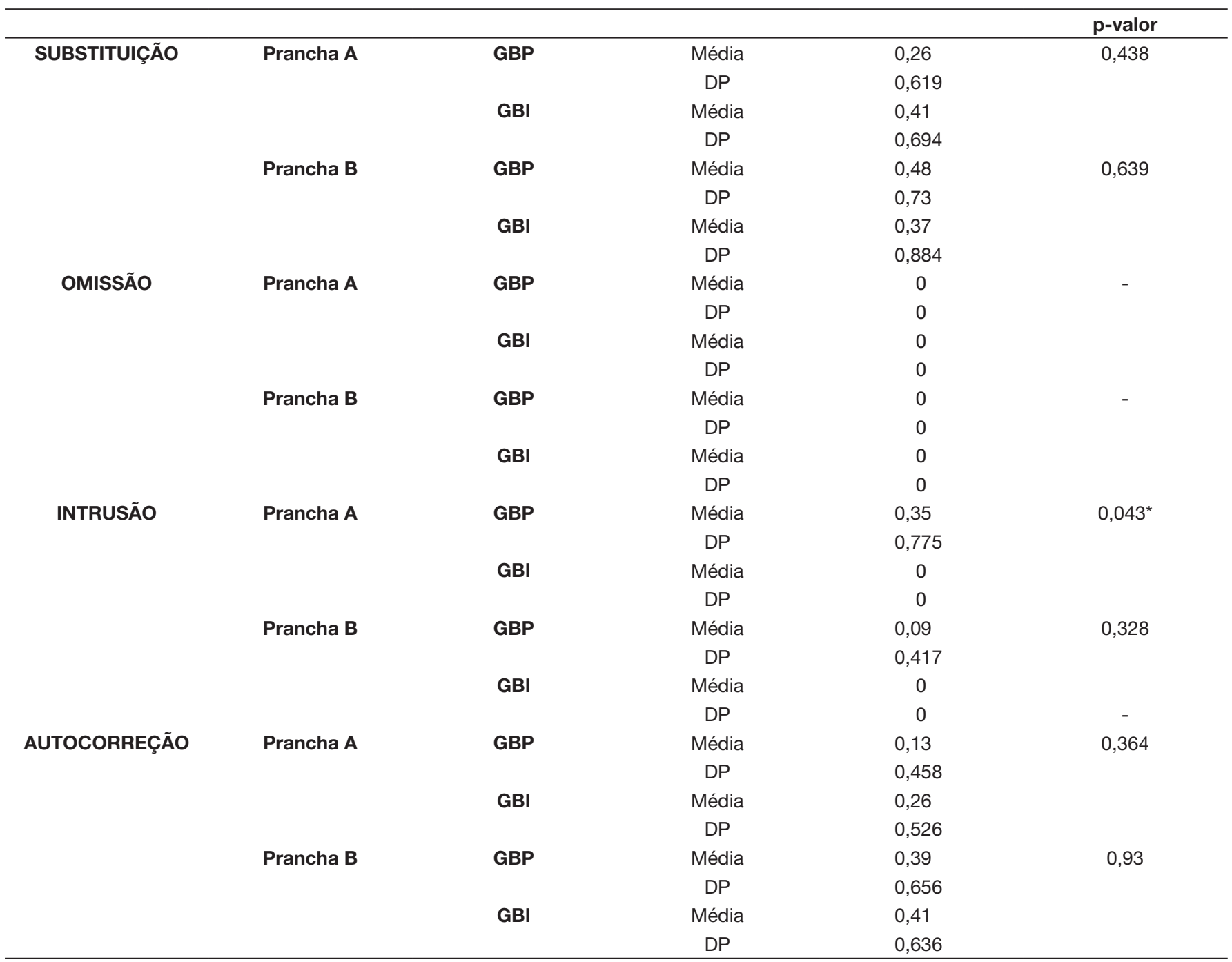

*Nível de significância: $p=0,05$ - Teste ANOVA

Legenda: GBP = Grupo Bilíngue Português; GBI = Grupo Bilíngue Inglês; DP = Desvio-padrão

Tabela 3. Análise das médias e desvios-padrão para cada tipo de erro na Nomeação Rápida, em Português, para GM e GB

\begin{tabular}{|c|c|c|c|c|c|}
\hline & & & & & p-valor \\
\hline \multirow[t]{8}{*}{ HESITAÇÃO } & Prancha A & GM & Média & 0,234 & $0,003^{*}$ \\
\hline & & & Desvio-padrão & 0,519 & \\
\hline & & GB & Média & 10,88 & \\
\hline & & & Desvio-padrão & 1,349 & \\
\hline & Prancha B & GM & Média & 0,38 & 0,772 \\
\hline & & & Desvio-padrão & 0,768 & \\
\hline & & GB & Média & 0,34 & \\
\hline & & & Desvio-padrão & 0,688 & \\
\hline \multirow[t]{8}{*}{ REPETIÇÃO } & Prancha A & GM & Média & 0,128 & 0,069 \\
\hline & & & Desvio-padrão & 0,494 & \\
\hline & & GB & Média & 0,46 & \\
\hline & & & Desvio-padrão & 1,163 & \\
\hline & Prancha B & GM & Média & 0,4 & 0,551 \\
\hline & & & Desvio-padrão & 1,313 & \\
\hline & & GB & Média & 0,56 & \\
\hline & & & Desvio-padrão & 1,248 & \\
\hline
\end{tabular}

*Nível de significância: $p=0,05$ - Teste ANOVA

Legenda: $\mathrm{GB}=$ Grupo Bilíngue; $\mathrm{GM}=$ Grupo Monolíngue 
Tabela 3. Continuação...

\begin{tabular}{|c|c|c|c|c|c|}
\hline & & & & & p-valor \\
\hline \multirow[t]{8}{*}{ SUBSTITUIÇÃO } & Prancha A & GM & Média & 0,17 & 0,09 \\
\hline & & & Desvio-padrão & 0,433 & \\
\hline & & GB & Média & 0,4 & \\
\hline & & & Desvio-padrão & 0,833 & \\
\hline & Prancha B & GM & Média & 0,45 & 0,856 \\
\hline & & & Desvio-padrão & 0,686 & \\
\hline & & GB & Média & 0,42 & \\
\hline & & & Desvio-padrão & 0,758 & \\
\hline \multirow[t]{8}{*}{ OMISSÃO } & Prancha A & GM & Média & 0,021 & 0,442 \\
\hline & & & Desvio-padrão & 0,145 & \\
\hline & & GB & Média & 0,06 & \\
\hline & & & Desvio-padrão & 0,313 & \\
\hline & Prancha B & GM & Média & 0,04 & 0,748 \\
\hline & & & Desvio-padrão & 0,292 & \\
\hline & & GB & Média & 0,06 & \\
\hline & & & Desvio-padrão & 0,24 & \\
\hline \multirow[t]{8}{*}{ INTRUSÃO } & Prancha A & GM & Média & 0 & 0,182 \\
\hline & & & Desvio-padrão & 0 & \\
\hline & & GB & Média & 0,06 & \\
\hline & & & Desvio-padrão & 0,313 & \\
\hline & Prancha B & GM & Média & 0,06 & 0,083 \\
\hline & & & Desvio-padrão & 0,247 & \\
\hline & & GB & Média & 0 & \\
\hline & & & Desvio-padrão & 0 & \\
\hline \multirow[t]{8}{*}{ AUTOCORREÇÃO } & Prancha A & GM & Média & 0,787 & 0,399 \\
\hline & & & Desvio-padrão & 0,931 & \\
\hline & & GB & Média & 0,62 & \\
\hline & & & Desvio-padrão & 1,007 & \\
\hline & Prancha B & GM & Média & 0,79 & 0,865 \\
\hline & & & Desvio-padrão & 1,02 & \\
\hline & & GB & Média & 0,82 & \\
\hline & & & Desvio-padrão & 0,873 & \\
\hline
\end{tabular}

*Nível de significância: $p=0,05$ - Teste ANOVA

Legenda: GB = Grupo Bilíngue; GM = Grupo Monolíngue

Tabela 4. Correlações de Spearman entre a variável Tempo despendido na Nomeação Rápida e Velocidade de Leitura para o GB (N=50)

\begin{tabular}{cccc}
\hline GB & Tempo despendido & $\begin{array}{c}\text { Velocidade de } \\
\text { Leitura }\end{array}$ \\
\hline $\begin{array}{c}\text { Nomeação Rápida } \\
\text { Inglês }\end{array}$ & $\begin{array}{c}\text { Correlação } \\
\text { Sig. (p) }\end{array}$ & $-0,454^{* *}$ \\
& $\mathbf{n}$ & 0,001 \\
& $\begin{array}{c}\text { Tempo despendido } \\
\text { Nomeação Rápida } \\
\text { Português }\end{array}$ & $\begin{array}{c}\text { Coeficiente de } \\
\text { Correlação } \\
\text { Sig. (p) }\end{array}$ & $-0,069$ \\
& $\mathbf{n}$ & 0,633 \\
& & 50 \\
\hline
\end{tabular}

** Nível de significância: $p=0,05$ - Teste Coeficiente de Correlação de Spearman

Legenda: GB = Grupo Bilíngue

diferenças de desempenho entre os grupos para as demais variáveis.

A investigação das correlações entre o acesso lexical e o número de palavras lidas por minuto foi realizada a partir da análise do tempo despendido na nomeação e do total de erros encontrados na prova de Nomeação Rápida para cada um dos grupos.

Não foram observadas correlações entre o número total de erros e o número de palavras lidas por minuto para o GB em Inglês ou para Português.

Por outro lado, encontrou-se correlação (negativa) significante para a análise do tempo despendido na Nomeação Rápida e o número de palavras lidas por minuto para o GB na prova realizada em Inglês (Tabela 4) No entanto, não foi encontrada correlação significativa para a análise em Português.

\section{DISCUSSÃO}

A alternância da língua é um comportamento naturalmente observado no indivíduo bilíngue. O falante bilíngue eficiente é capaz de identificar o contexto comunicativo e controlar a utilização de seus idiomas, mantendo-os completamente separados ou permitindo maior flexibilidade em comunicação ${ }^{(18)}$. Ao considerarmos os mecanismos de acesso lexical do cérebro do indivíduo bilíngue, no qual ocorre a ativação paralela das 
representações lexicais de ambas as línguas, entendemos que o processo de alternância de língua é complexo e demanda controle sobre diversos processos $\operatorname{cognitivos}^{(9)}$ e, por vezes, a alternância de língua pode interferir negativamente sobre o desempenho do falante ${ }^{(19)}$.

A comparação entre o tempo despendido na nomeação pelos grupos bilíngues revelou pior desempenho para as segundas tarefas de nomeação realizadas (Tabela 1), independentemente da língua utilizada na segunda nomeação. Ou seja, os escolares do grupo bilíngue despenderam mais tempo para realizar a prova de nomeação rápida em condição de alternância da língua. Esses resultados demonstram que, em bilíngues, o desempenho linguístico de acesso ao léxico pode sofrer impacto negativo da alternância da língua em tarefa de nomeação rápida. De fato, as pesquisas têm apontado que bilíngues cometem mais erros e são mais lentos quando submetidos a atividades que envolvem a alternância de línguas em relação ao desempenho em atividades de produção em apenas uma língua ${ }^{(20-22)}$.

Este estudo também investigou a influência do fenômeno de alternância de línguas sobre a acurácia da nomeação rápida, a partir da análise do número e natureza de erros cometidos. Foi identificada diferença de desempenho para os grupos GBP e GBI na nomeação da Prancha A, em Inglês, sendo ela encontrada apenas para os erros de hesitação, repetição e intrusão. Ao realizar a nomeação em Inglês, o grupo GBP apresentou maior número de erros, quando comparado ao grupo GBI na mesma atividade.

Esse resultado corrobora a hipótese de que a alternância de línguas afeta o desempenho linguístico do indivíduo bilíngue ${ }^{(19)}$. Quando realizada a alternância de línguas, os escolares despenderam mais tempo para nomear e apresentaram maior número de erros.

A natureza dos erros encontrados igualmente configura um dado interessante. Em comparação ao GM, o GB também apresentou diferenças de desempenho para os tipos de erros cometidos na tarefa de nomeação em Português. O GB apresentou maior número de erros de hesitação, mas apresentou desempenho semelhante ao GM para todos os outros erros analisados.

O padrão de erros observado na comparação entre GBP e GBI pode ser explicado pelo fenômeno de alternância de línguas, assim como referido pela literatura pertinente ${ }^{(19-22)}$. Por outro lado, as hesitações identificadas na comparação entre GM e GB levantam a hipótese de que o desempenho do GB possa ter sido prejudicado por prejuízos no acesso ao léxico mental ${ }^{(23)}$.

Sabe-se que, no cérebro de indivíduos bilíngues, ambas as línguas são ativadas nos momentos em que são realizadas produções em qualquer de suas línguas ${ }^{(8,9)}$ e as representações lexicais são distintas para cada uma delas ${ }^{(10)}$. Dessa forma, o indivíduo bilíngue precisa selecionar a língua relevante e inibir a outra o que, ao longo da vida, propiciaria o aperfeiçoamento de suas habilidades executivas ${ }^{(12,24,25)}$. Um bom controle inibitório e um mecanismo atencional bem estabelecido são habilidades necessárias para que os bilíngues sejam capazes de realizar atividades linguísticas que demandem, mesmo, o uso de apenas uma língua(26).

No entanto, apesar de serem reportados benefícios de controle executivo para o indivíduo bilíngue ${ }^{(12,24,25)}$, também são encontrados déficits de acesso lexical, especialmente em tarefas de acesso rápido de itens lexicais ${ }^{(23)}$, como ocorre na tarefa de nomeação automática rápida (RAN). Além de demandar mecanismos atencionais, também há grande demanda verbal durante a realização de tarefas RAN, já que indivíduos bilíngues acessam o dobro de representações lexicais.

Assim, é possível levantar a hipótese de que as dificuldades de acesso lexical apresentadas por indivíduos bilíngues podem ter se refletido em maior número de hesitações e autocorreções em seu desempenho na nomeação rápida.

Por outro lado, as hesitações e autocorreções apresentadas na RAN não necessariamente se refletem em prejuízos para situações de processamento linguístico mais generalizado ${ }^{(23)}$. As hesitações, ou pausas no discurso, podem estar presentes em maior ou menor grau no discurso de indivíduos e, para bilíngues, essas rupturas podem ser, até, um recurso necessário ao falarem uma segunda língua ${ }^{(13)}$.

Embora seja uma atividade de natureza diferente, pesquisadores que examinaram o papel dessas rupturas (hesitações, repetições, autocorreções ou reformulações, automatismos) do discurso espontâneo sugeriram que mesmo indivíduos bilíngues altamente fluentes produzem mais hesitações quando falam em sua segunda língua ${ }^{(27)}$. A literatura indica que quando o indivíduo bilíngue está falando em L2, seu discurso torna-se menos automático o que, pode resultar em aumento do tempo de planejamento e do número de correções. Dessa forma, as hesitações no discurso podem ser uma estratégia positiva, uma vez que ajudam a aumentar o tempo de planejamento e facilitam a comunicação ${ }^{(28)}$.

Também verificamos a existência de correlações entre o acesso lexical e o número de palavras lidas por minuto por meio da análise do desempenho dos escolares na prova de nomeação rápida quanto ao tempo despendido e erros encontrados.

A velocidade de acesso lexical e o número de palavras lidas por minuto estiveram correlacionados no GB, mas não no GM. A análise mostrou, somente para o GBI, correlação negativa entre o tempo despendido na Nomeação Rápida em Inglês e o número de palavras lidas por minuto. Ou seja, quanto menor foi o tempo despendido na nomeação em Inglês, maior foi o número de palavras lidas por minuto em Português.

Os resultados mostraram que os tipos ou a quantidade de erros encontrados na nomeação rápida não estiveram relacionados ao desempenho no número de palavras lidas por minuto nos demais grupos. Esses achados discordam da literatura ${ }^{(29)}$, segundo a qual a habilidade de nomeação rápida é um preditor significante da velocidade de leitura tanto para o grupo monolíngue, quanto para o grupo bilíngue.

Em relação às limitações do estudo, é importante ressaltar que a metodologia determinou a leitura de frases para a inclusão das crianças na amostra. Dessa forma, as habilidades cognitivas relacionadas à interpretação e compreensão de frases podem ter interferido no desempenho em velocidade de leitura, o que pode, a sua vez, ter influenciado os resultados quanto à relação entre a taxa de leitura e a habilidade de nomeação automática rápida. Adicionalmente, a ausência de informações referentes ao nível socioeconômico dos escolares também configurou uma importante limitação deste estudo. 


\section{CONCLUSÃO}

Escolares brasileiros bilíngues apresentaram pior desempenho em tarefa de nomeação rápida em situação de alternância de línguas em tempo e acurácia. Também apresentam pior desempenho em tarefa de nomeação automática rápida, quando comparados a escolares monolíngues, demonstrando maior número de erros, especialmente hesitações. Somente o desempenho dos escolares bilíngues na prova de nomeação rápida em L2 correlacionou-se com a taxa de leitura em L1.

\section{AGRADECIMENTOS}

À FAPESP, pela bolsa concedida.

\section{REFERÊNCIAS}

1. Kay-Raining Bird E, Genesee F, Verhoeven L. Bilingualism in children with developmental disorders: a narrative review. J Commun Disord. 2016;63:1-14. http://dx.doi.org/10.1016/j.jcomdis.2016.07.003. PMid:27461977.

2. Peal E, Lambert WE. The relation of bilingualism to intelligence. Psychol Monogr Gen Appl. 1962;76(27):1-23. http://dx.doi.org/10.1037/h0093840.

3. Young S. The effects of bilingualism and multilingualism on lexical retrieval [Internet]. Cedarville: Cedarville University; 2016.(Linguistics Senior Research Projects; 6) [cited 2007 Feb 22]. Available from: https:// digitalcommons.cedarville.edu/linguistics_senior_projects/6

4. Engel de Abreu PMJ. Working memory in multilingual children: is there a bilingual effect? Memory. 2011;19(5):529-37. http://dx.doi.org/10.108 0/09658211.2011.590504. PMid:21864216.

5. Gollan TH, Montoya RI, Werner GA. Semantic and letter fluency in Spanish-English bilinguals. Neuropsychology. 2002;16(4):562-76. http:// dx.doi.org/10.1037/0894-4105.16.4.562.

6. Roberts PM, Garcia LJ, Desrochers A, Hernandez D. English performance of proficient bilingual adults on the Boston Naming Test. Aphasiology. 2002;16(4-6):635-45. http://dx.doi.org/10.1080/02687030244000220.

7. Logan JAR, Schatschneider C, Wagner RK. Rapid serial naming and reading ability: the role of lexical access. Read Writ. 2011;24(1):1-25. http://dx.doi.org/10.1007/s11145-009-9199-1. PMid:22215934.

8. Shook A, Marian V. Bimodal bilinguals co-activate both languages during spoken comprehension. Cognition. 2012;124(3):314-24. http://dx.doi. org/10.1016/j.cognition.2012.05.014. PMid:22770677.

9. Kroll JF, Bobb SC, Misra M, Guo T. Language selection in bilingual speech: evidence for inhibitory processes. Acta Psychol (Amst). 2008;128(3):41630. http://dx.doi.org/10.1016/j.actpsy.2008.02.001. PMid:18358449.

10. Gollan TH, Montoya RI, Fennema-Notestine C, Morris SK. Bilingualism affects picture naming but not picture classification. Mem Cognit. 2005;33(7):1220-34. http://dx.doi.org/10.3758/BF03193224.

11. Lúcio PS, Kida ABS, Carvalho CAF, Cogo-Moreira H, Avila CRB. Prova de nomeação rápida de figuras para crianças: evidências de validade e normas intragrupo. Psico-USF. 2017;22(1):35-47. http://dx.doi.org/10.1590/141382712017220104.

12. Meuter RFI, Allport A. Bilingual language switching in naming: asymmetrical costs of language selection. J Mem Lang. 1999;40(1):25-40. http://dx.doi. org/10.1006/jmla.1998.2602.

13. Færch C, Kasper G. Strategies in interlanguage communication [Internet]. London: Longman; 1983. 253 p. [cited 2019 Feb 3]. Available from: https:// archive.org/details/strategiesininte00frch
14. Gottardo A, Grant A. (2008). Defining bilingualism. In: Sénéchal M, editor Encyclopedia of language and literacy development [Internet]. London, ON: Canadian Language and Literacy Research Network; 2019. p. 1-7 [cited 2019 Feb 3]. Available from: http://www.literacyencyclopedia.ca/ pdfs/topic.php?topId=236

15. Norton ES, Wolf M. Rapid Automatized Naming (RAN) and reading fluency: implications for understanding and treatment of reading disabilities. Annu Rev Psychol. 2012;63(1):427-52. http://dx.doi.org/10.1146/annurevpsych-120710-100431. PMid:21838545.

16. Georgiou GK, Parrila R, Liao C-H. Rapid naming speed and reading across languages that vary in orthographic consistency. Read Writ. 2008;21(9):885903. http://dx.doi.org/10.1007/s11145-007-9096-4.

17. Kohn SE, Goodglass H. Picture-naming in aphasia. Brain Lang. 1985;24(2):26683. http://dx.doi.org/10.1016/0093-934X(85)90135-X. PMid:3978406.

18. Liu Y, Chang S, Li L, Liu W, Chen D, Zhang J, et al. Effectos of naming language and switch predictability on switch costs in bilingual language production. Front Psychol. 2018;9:649. http://dx.doi.org/10.3389/ fpsyg.2018.00649. PMid:29910748.

19. Fink A, Goldrick M. Pervasive benefits of preparation in language switching. Psychon Bull Rev. 2015;22(3):808-14. http://dx.doi.org/10.3758/s13423014-0739-6. PMid:25257712.

20. Christoffels IK, Firk C, Schiller NO. Bilingual language control: an eventrelated brain potential study. Brain Res. 2007;1147:192-208. http://dx.doi. org/10.1016/j.brainres.2007.01.137. PMid:17391649.

21. Gollan TH, Ferreira VS. Should I stay or should I switch? A cost-benefit analysis of voluntary language switching in young and aging bilinguals. J Exp Psychol Learn Mem Cogn. 2009;35(3):640-65. http://dx.doi.org/10.1037/ a0014981. PMid:19379041.

22. Weissberger GH, Wierenga CE, Bondi MW, Gollan TH. Partially overlapping mechanisms of language and task control in young and older bilinguals. Psychol Aging. 2012;27(4):959-74. http://dx.doi.org/10.1037/a0028281. PMid:22582883.

23. Bialystok E, Craik F, Luk G. Cognitive control and lexical access in younger and older bilinguals. J Exp Psychol Learn Mem Cogn. 2008;34(4):859-73. http://dx.doi.org/10.1037/0278-7393.34.4.859. PMid:18605874.

24. Rodriguez-Fornells A, De Diego Balaguer R, Münte TF. Executive control in bilingual language processing. Lang Learn. 2006;56:133-90. http:// dx.doi.org/10.1111/j.1467-9922.2006.00359.x.

25. Abutalebi J, Green D. Bilingual language production: the neurocognition of language representation and control. J Neurolinguist. 2007;20(3):24275. http://dx.doi.org/10.1016/j.jneuroling.2006.10.003.

26. Poarch GJ, van Hell JG. Executive functions and inhibitory control in multilingual children: evidence from second-language learners, bilinguals, and trilinguals. J Exp Child Psychol. 2012;113(4):535-51. http://dx.doi. org/10.1016/j.jecp.2012.06.013. PMid:22892367.

27. Fehringer C, Fry C. Hesitation phenomena in the language production of bilingual speakers: the role of working memory. Folia Linguist. 2007;41(12):37-72. http://dx.doi.org/10.1515/flin.41.1-2.37.

28. Wiese R. Language production in foreign and native languages: same or different? In Dechert HW, Möhle D, Raupach M, editors. Second language productions. Tubingen: Narr Verlag; 1984. p. 11-25.

29. Bellocchi S, Tobia V, Bonifacci P. Predictors of reading and comprehension abilities in bilingual and monolingual children: a longitudinal study on a transparent language. Read Writ. 2017;30(6):1311-34. http://dx.doi. org/10.1007/s11145-017-9725-5.

\section{Contribuição dos autores}

ES foi responsável pela concepção da pesquisa, coleta, análise dos dados e escrita final do artigo; CRBA foi responsável pelo desenho da pesquisa, análise e interpretação dos dados, aprovação final da versão a ser publicada; $A T H B$ colaborou no desenho metodológico, com a coleta e análise dos dados. 